\section{Back to basics for HIV vaccine development}

The US programme to develop an HIV vaccine will shift funding back towards basic research and away from clinical trials of candidate vaccines, officials at the National Institutes of Health announced last week.

The decision follows the discontinuation last year of trials for Merck's candidate HIV vaccine, in which participants showed higher rates of HIV infection than the

\section{Tasting a geyser}

The geyser of ice and water vapour erupting from the south pole of Enceladus, a tiny moon of Saturn, contains complex organic molecules, NASA scientists have discovered.

The Cassini spacecraft flew through the plume on 12 March and got its first good taste of the jet's chemistry - which is unexpectedly similar to that of a comet.

The flyby results, reported on 26 March, also include thermal images of the four long cracks from which the plume emanates. At their hottest, the cracks were $93^{\circ} \mathrm{C}$ warmer than the rest of the moon, indicating underground reservoirs of liquid water. This all suggests that Enceladus formed differently from, and probably later than, the rest of the Saturn system. unvaccinated population. Merck's was one of only three vaccines to make it to largescale clinical trials. A second had already failed, and there are doubts about the ability of the third to stimulate the immune system.

The vaccine pipeline needs refilling, National Institute of Allergy and Infectious Diseases director Anthony Fauci said on 25 March. "We need to turn the knob in the direction of discovery - that is unambiguous."

See Editorial, page 503.

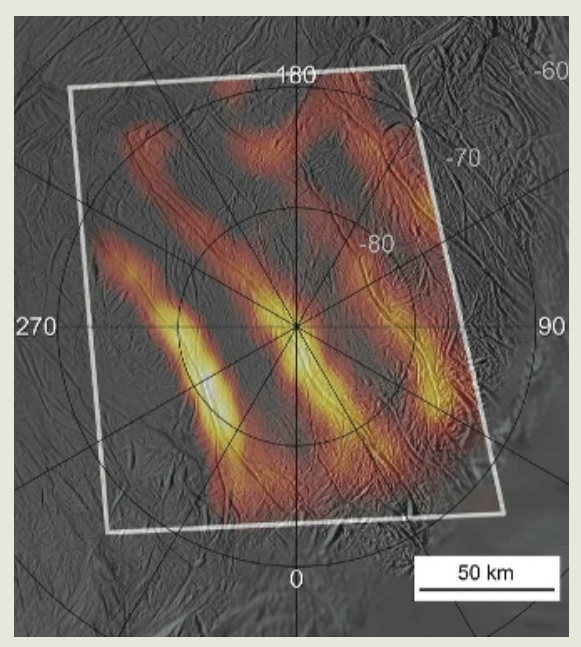

US medical school to require master's degree

The Scripps Research Institute and its clinical partners are forming the first US medical school that will require applicants to have a master's degree. Scripps, which is based in La Jolla, California, expects to enrol its first 40 students in 2010.

"The master's will be in translational medicine," says Scripps cardiologist Eric Topol, the school's founding dean. "Our mission is to encourage a new genre of physician-investigator."

The medical training will take place in existing facilities, but Scripps is seeking philanthropic support for much of the school's \$150-million cost, Topol says.

Many US medical schools offer combined MD-PhD programmes for some students, but Scripps is the first to make a master's degree a requirement.

\section{Too much haste in US drug approval?}

The US Food and Drug Administration (FDA) may be issuing shaky last-minute drug approvals, according to a new study. In an article in the New England Journal of 
Medicine ((D. Carpenter et al. N. Engl. J. Med. 358, 1354-1361; 2008), Daniel Carpenter and his colleagues at Harvard University studied 313 drugs approved for market between 1993 - when drug companies began paying for reviews, and penalties came in for the agency missing deadlines - and 2004.

They found that $14 \%$ of drugs approved in the two months before deadlines had serious safety problems requiring 'black box' label warnings, market withdrawals, or both, compared with $3.2 \%$ approved earlier in the process. The FDA is disputing Carpenter's figures.

\section{Italy to help Kenya develop space programme}

The Italian Space Agency, which operates a tracking station in Kenya, will give the country access to geospatial data and training in satellite systems.

Under an agreement signed on 28 March, six Kenyan scientists and engineers will travel to Rome to help build MIOSAT, an Earth-observation satellite. Italy will also set up a centre in Kenya to give scientists there access to Earth-observing data. The project is expected to cost the Italian government some $€ 200,000$ (US\$315,000).

The agreement is a major step forward

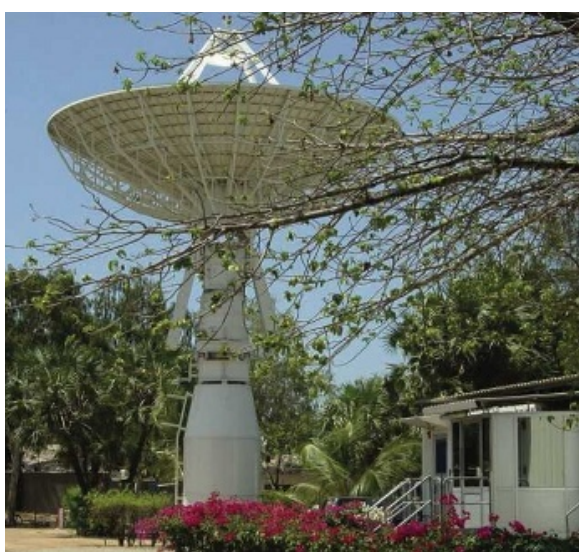

Italy runs a tracking station in Malindi, Kenya.

for Kenya's nascent space programme, says Zachary Mwaura, the country's secretary for defence. "This is something that we have really, really been looking forward to," he says.

\section{Muslim nations raise status of science}

Science is being taken more seriously in the Organisation of the Islamic Conference (OIC), a group of 57 states.

The OIC's standing committee on science and technology (COMSTECH) is set to announce this week that only countries committed to donating funds will be allowed to join the committee. Payment will be in proportion to gross domestic product, at a rate set by the OIC.

COMSTECH will use the money to launch programmes for its members in areas such as biotechnology, development of pharmaceuticals from indigenous raw materials, and science policy.

Until now, COMSTECH has been open to all OIC members, but few gave any money. Last year, only US\$2.59 million was taken from 13 states - most of it from Pakistan which was used to support library services.

Atta-ur-Rahman, who heads both COMSTECH and Pakistan's Higher Education Commission, expects up to 15 countries to join this year, with more joining in the future. "Most of the Muslim countries don't have national science policies based on their local needs and available resources," he says. "COMSTECH will help them."

\section{Correction}

Our News story on the Quake-Catcher Network (Nature 452, 397; 2008) should have noted that the concept originated with Elizabeth Cochran, a geophysicist at the University of California, Riverside, and that the project is now an ongoing collaboration between her and seismologist Jesse Lawrence of Stanford University in California. 